\title{
KESIAPAN PULANG PASIEN PENYAKIT JANTUNG KORONER MELALUI PENERAPAN DISCHARGE PLANNING
}

\author{
Aria Wahyuni ${ }^{1,2^{*}}$, Elly Nurrachmah ${ }^{3}$, Dewi Gayatri ${ }^{3}$ \\ 1. STIKES Fort De Kock Bukittinggi Keperawatan Medikal Bedah, Bukittinggi 26181, Indonesia \\ 2. Program Studi Magister Fakultas Ilmu Keperawatan Universitas Indonesia, Depok 16424, Indonesia \\ 3. Fakultas Ilmu Keperawatan Universitas Indonesia, Depok 16424, Indonesia \\ *Email: ariawahyuni@yahoo.com
}

\begin{abstract}
Abstrak
Penyakit Jantung Koroner (PJK) adalah suatu bentuk gangguan pembuluh darah koroner yang termasuk dalam ketegori arterosklerosis. Ketidaksiapan pasien PJK pulang dari rumah sakit akan berdampak terhadap rawatan ulang sebagai akibat dari pelaksanaan program discharge planning yang belum efektif selama dirawat. Penelitian ini bertujuan untuk mengetahui pengaruh penerapan discharge planning terhadap kesiapan pulang pasien penyakit jantung koroner. Penelitian ini menggunakan desain quasi experiment dengan pendekatan non-equivalent post test only control group design. Jumlah sampel 32 orang yang terbagi atas 16 orang kelompok kontrol dan 16 orang kelompok intervensi dan dilakukan di tiga rumah sakit di Kota Bukittinggi. Hasil penelitian didapatkan adanya pengaruh penerapan discharge planning terhadap kesiapan pulang pasien penyakit jantung koroner yang terdiri dari status personal, pengetahuan, kemampuan koping, dan dukungan $(p=0,001 ; \alpha=0,05)$. Penelitian ini merekomendasikan discharge planning yang baik dapat dilakukan untuk meningkatkan kualitas asuhan keperawatan dan kualitas hidup pasien penyakit jantung koroner.
\end{abstract}

Kata Kunci: discharge planning, kesiapan pulang, penyakit jantung koroner

\section{Abstract}

Coronary Heart Disease (CHD) is a form of blood vessel disorder that belongs to the category of coronary atherosclerosis. An unreadiness of patients with CHD to go home from the hospital will have an impact on readmission as a result of ineffective discharge planning program during hospitalized. The purpose of this study was to examine the effect of the implementation of discharge planning program on the readiness to be discharged from the hospital. A quasi experiment with non-equivalent post test only control group design was employed. The participant of the study was 32 respondents devided into control and intervention groups, each had 16 respondents who were taken from three hospitals in Bukittingi. The result showed that discharge planning program has significance influence on patient's perception of their readiness to be discharged from the hospital, it consisting of personal status, knowledge, coping ability, and support ( $p=0.001 ; \alpha=0.05$ ). This study recommends that a good discharge planning program can be implemented to improve the quality of nursing care, to reduce the risk of readmission to the hospital and the quality of life of patients with coronary heart diseases.

Keywords: coronary heart disease, discharge planning, readiness to be discharged

\section{Pendahuluan}

Penyakit Jantung Koroner merupakan gangguan pada pembuluh darah koroner berupa penyempitan atau penyumbatan yang dapat mengganggu proses transportasi bahan-bahan energi tubuh, sehingga dapat mengakibatkan terjadi ketidakseimbangan antara suplai oksigen dan kebutuhan oksigen. Ketidakseimbangan ini menimbulkan gangguan pompa jantung dan berakhir pada kelemahan dan kematian sel-sel jantung. Penyakit Jantung Koroner (PJK) termasuk bagian penyakit kardiovaskular dan merupakan penyakit yang menjadi "wabah" di dunia modern saat ini. Laporan World Health Organization (WHO) pada September 2009 menyebutkan bahwa penyakit jantung koroner merupakan penyebab kematian pertama saat ini (Yahya, 2010).

Program discharge planning merupakan suatu proses mempersiapkan pasien untuk mendapatkan kontinuitas dalam perawatan dan mempertahankan derajat kesehatannya sampai pasien merasa siap untuk kembali ke lingkungan keluarganya, proses tersebut dimulai sejak awal pasien datang ke sebuah tempat pelayanan kesehatan (Cawthorn, 2005). 
Program discharge planning yang diberikan sejak pasien masuk rumah sakit dapat meningkatkan perkembangan kondisi kesehatan dan membantu pasien mencapai kualitas hidup optimum sebelum dipulangkan. Ketidaktahuan atau ketidakmampuan pasien dan keluarga mengenai cara perawatan di rumah berdampak pada masalah kesehatan atau ketidaksiapan pasien menghadapi pemulangan setelah pasien dirawat di rumah sakit. Hal tersebut menyebabkan risiko peningkatan komplikasi dan berakibat kepada hospitalisasi ulang (Potter \& Perry, 2006).

Data yang ada saat ini di ketiga rumah sakit di Kota Bukittinggi pada 2010 bahwa terdapat 10\% pasien PJK yang dirawat mengalami rawatan ulang. Diperkirakan bahwa salah satu penyebab terjadinya rawatan ulang yaitu kemungkinan ketidaksiapan pasien pulang ke rumah dengan rata-rata rentang pasien PJK yang mengalami rawatan ulang dari rawatan sebelumnya tiga sampai enam bulan.

Mengingat penerapan program discharge planning merupakan hal yang penting untuk meningkatkan kualitas hidup pasien sebelum pulang dan untuk mempersiapkan pasien pulang serta meningkatkan keselamatan pasien. Maka peneliti melakukan penelitian tentang "Pengaruh Penerapan Discharge Planning terhadap Kesiapan Pulang Pasien PJK di Rumah Sakit Kota Bukittinggi’. Penelitian ini bertujuan untuk mengetahui pengaruh penerapan program discharge planning terhadap kesiapan pulang pasien penyakit jantung koroner yang terdiri status personal, pengetahuan, kemampuan koping, dan dukungan.

\section{Metode}

Penelitian menggunakan desain quasi experiment dengan pendekatan non-equivalent post-test only control group design, dengan jumlah sampel 32 orang yang terdiri masing-masing 16 orang untuk kelompok kontrol dan intervensi. Adapun sampel yang dipilih memenuhi kriteria inklusi antara lain bersedia menjadi responden, pasien PJK yang baru masuk ruang perawatan (hari pertama dirawat), kesadaran komposmentis dan dalam keadaan tenang, tidak dimensia atau gangguan kognitif. Penelitian ini dilakukan di ruang ICCU/ICU, ruang rawat inap (ruang jantung dan ruang interna) di tiga rumah sakit Kota Bukittinggi. Waktu pengumpulan data dilaksanakan pada November-Desember 2011. Penelitian ini dilakukan dengan memegang lima prinsip etik yaitu self determination, privacy and anonymity, beneficience, maleficence, and justice.

Discharge planning dilakukan selama tujuh hari pasien dirawat di rumah sakit. Pada kelompok kontrol proses penelitian dengan memberikan discharge planning sesuai kondisi rumah sakit dari hari pertama sampai keenam. Pada hari keenam tersebut pasien diberikan leaflet tentang PJK pada pasien, rerata 4 jam pasien sebelum dipulangkan peneliti mengkaji kesiapan pulang pasien PJK dengan meminta pasien mengisi RHDS (Readiness for Hospital Discharge Scala).

Pada kelompok intervensi discharge planning yang disusun peneliti dimulai pada hari pertama sampai hari ketujuh pasien dirawat; Hari pertama: pasien dan keluarga diorientasikan terlebih dahulu, membina hubungan saling percaya dan diberikan buku pedoman PJK setelah itu rehabilitasi jantung tahap I pada hari pertama dimulai; Hari kedua: pengkajian kebutuhan persiapan pulang pasien, rehabilitasi jantung tahap I hari kedua; Hari ketiga: pemberian pendidikan kesehatan (anatomi dan fisiologi jantung, dan penyakit jantung koroner), rehabilitasi jantung tahap I pada hari ketiga; Hari keempat: pemberian pendidikan kesehatan (pemeriksaan pada PJK, dan pengobatan PJK), rehabilitasi jantung tahap I pada hari keempat; Hari kelima: pemberian pendidikan kesehatan (modifikasi lingkungan), rehabilitasi jantung tahap I pada hari kelima diruang rawat inap; Hari keenam: pemberian pendidikan kesehatan (program rehabilitasi jantung dan tempat pelayanan kesehatan jantung), rehabilitasi jantung tahap I pada hari keenam; Hari ketujuh, yaitu evaluasi keperawatan, rehabilitasi jantung tahap I hari ketujuh, persiapan pulang pasien (obat-obatan, 
daftar diet, jadwal kontrol), dilanjutkan dengan peneliti mengukur kesiapan pulang menggunakan instrumen RHDS pada kelompok intervensi pada empat jam pasien sebelum dipulangkan. Pada saat empat jam pasien akan dipulangkan peneliti memberikan RHDS untuk mengukur kesiapan pulangnya, penelitian dimulai pada kelompok kontrol selanjutnya kelompok intervensi.

RHDS ini dikembangkan Weiss dan Piacentine pada 2006, digunakan untuk menilai kesiapan pulang pasien, dan pada penelitian ini peneliti memfokuskan pada kesiapan pulang pasien PJK. Jumlah item pertanyaan dari kesiapan pulang dalam RHDS yaitu 23 pertanyaan yang diukur menggunakan skala $0-10(0=$ tidak siap sama sekali untuk pulang sampai $230=$ benar-benar siap untuk pulang). Kesiapan pulang pada RHDS dibagi dalam empat komponen antara lain; status personal, pengetahuan, kemampuan koping, dan dukungan. Status personal jumlah item pertanyaan adalah 7 item $(0=$ lemah sampai $70=$ sangat kuat $)$, pengetahuan 7 item $(0=$ tidak tahu sampai $7=$ sangat tahu), kemampuan koping 4 item ( $0=$ tidak mampu sampai $40=$ sangat mampu), dan dukungan 5 item $(0=$ tidak ada dukungan sampai $50=$ ada banyak dukungan).

\section{Hasil}

Hasil analisis univariat karakteristik pasien PJK di tiga rumah sakit Kota Bukittinggi didapatkan rerata umur pada kelompok kontrol dan kelompok intervensi adalah 53,50 tahun (95\% CI : 48,87; $58,13)$, dengan standar deviasi 12,84 tahun, umur termuda 24 tahun dan umur tertua 74 tahun. Karakteristik responden berdasarkan proporsi jenis kelamin sebagian besar berjenis kelamin laki-laki yakni 20 orang $(62,5 \%)$.

Proporsi status perkawinan menunjukkan bahwa responden sebagian besar berstatus kawin yakni 30 orang $(93,8 \%)$, tingkat pendidikan diperoleh bahwa sebagian besar berpendidikan lanjut 22 orang (68,8\%). Proporsi banyaknya jumlah serangan PJK menunjukkan sebagian besar memiliki jumlah serangan $\mathrm{PJK} \geq 2$ kali yakni 18 orang $(56,2 \%)$ dijelaskan dalam tabel 1 .

Hasil analisis rata-rata kesiapan pulang pasien PJK meliputi status personal, pengetahuan, kemampuan koping, dan dukungan. Rata-rata kesiapan pulang kelompok kontrol adalah 100 dengan nilai terendah 91 dan nilai tertinggi 106. Sedangkan rata-rata kesiapan pulang kelompok intervensi adalah 208,31 dengan nilai terendah 197 dan nilai tertinggi 217. Sehingga rata-rata kesiapan pulang kelompok intervensi lebih tinggi dua kali dengan kelompok kontrol atau dengan perbedaan rata-rata 108,31.

Rata-rata status personal kelompok kontrol adalah 33,75, nilai terendah 30 dan tertinggi 36. Sedang rata-rata status personal kelompok intervensi adalah 63,88 , nilai terendah 61 dan nilai tertinggi 68. Sehingga rata-rata kesiapan pulang kelompok intervensi lebih tinggi 1,9 kali dengan kelompok kontrol atau dengan perbedaan rata-rata 30,13.

Rata-rata pengetahuan kelompok kontrol adalah 10,81 , nilai terendah 8 dan tertinggi 16 . Sedangkan rata-rata kesiapan pulang kelompok intervensi adalah 64,88, nilai terendah 60 dan nilai tertinggi 70. Sehingga rata-rata pengetahuan kelompok intervensi lebih tinggi 6 kali dengan kelompok kontrol atau dengan perbedaan rata-rata 54,06.

Rata-rata kemampuan koping kelompok kontrol adalah 22,38 dengan nilai terendah 19 dan nilai tertinggi 24. Sedangkan rata-rata kemampuan koping kelompok intervensi adalah 35,25 dengan nilai terendah 32 dan nilai tertinggi 39. Sehingga rata-rata kemampuan koping kelompok intervensi lebih tinggi 1,6 kali dengan kelompok kontrol atau dengan perbedaan rata-rata 12,88 .

Rata-rata dukungan kelompok kontrol adalah 33,06 dengan nilai terendah 22 dan nilai tertinggi 36 . Sedangkan rata-rata dukungan kelompok intervensi adalah 44,31, nilai terendah 42 dan nilai tertinggi 48 sehingga rata-rata kesiapan pulang kelompok intervensi lebih tinggi 1,3 kali dengan kelompok kontrol atau dengan perbedaan rata-rata 11,25. 
Tabel 1. Karakteristik Responden

\begin{tabular}{|c|c|c|c|c|c|c|c|}
\hline \multirow{2}{*}{ Variabel / Kelompok } & \multirow{2}{*}{$\mathbf{n}$} & \multirow{2}{*}{$\begin{array}{c}\text { Mean } \\
\text { (Tahun) }\end{array}$} & \multirow{2}{*}{ Median } & \multirow{2}{*}{ SD } & \multirow{2}{*}{ Min - Maks } & \multicolumn{2}{|c|}{$95 \% \mathrm{CI}$} \\
\hline & & & & & & \multicolumn{2}{|c|}{ Lower ; Upper } \\
\hline \multicolumn{8}{|l|}{ Umur } \\
\hline Kontrol & 16 & 52,44 & 53,00 & 16,13 & $24,00-74,00$ & \multicolumn{2}{|c|}{43,$84 ; 61,04$} \\
\hline Intervensi & 16 & 54,66 & 55,00 & 8,84 & $36,00-70,00$ & \multicolumn{2}{|c|}{49,$85 ; 55,27$} \\
\hline Gabungan & 32 & 53,50 & 54,00 & 12,84 & $24,00-74,00$ & \multicolumn{2}{|c|}{48,$87 ; 58,13$} \\
\hline \multirow{2}{*}{ Variabel } & \multicolumn{3}{|c|}{$\begin{array}{c}\text { Kontrol } \\
(n=16)\end{array}$} & \multicolumn{2}{|r|}{$\begin{array}{l}\text { In te rvensi } \\
\quad(n=16)\end{array}$} & \multicolumn{2}{|c|}{ Total } \\
\hline & $\mathbf{n}$ & & $\%$ & $\mathbf{n}$ & $\%$ & $\mathbf{n}$ & $\%$ \\
\hline \multicolumn{8}{|l|}{ Jen is Kelamin } \\
\hline Perempuan & 5 & & 31,2 & 7 & 43,8 & 12 & 37,5 \\
\hline Laki-laki & 11 & & 68,8 & 9 & 56,2 & 20 & 62,5 \\
\hline Total & 16 & & 100 & 16 & 100 & 32 & 100 \\
\hline \multicolumn{8}{|l|}{ Pendidikan } \\
\hline $\mathrm{SD}$ & 3 & & 18,75 & 1 & 6,25 & 4 & 12,5 \\
\hline SMP & 2 & & 12,50 & 4 & 25,0 & 6 & 18,8 \\
\hline SMU & 8 & & 50,0 & 9 & 56,25 & 17 & 53,1 \\
\hline PT / Akademik & 3 & & 18,75 & 2 & 12,50 & 5 & 15,6 \\
\hline Total & 16 & & 100 & 16 & 100 & 32 & 100 \\
\hline \multicolumn{8}{|l|}{ Status Perkawinan } \\
\hline Tidak berstatus kawin & 1 & & 6,2 & 1 & 6,2 & 2 & 6,2 \\
\hline Berstatus kawin & 15 & & 93,8 & 15 & 93,8 & 30 & 93,8 \\
\hline Total & 16 & & 100 & 16 & 100 & 32 & 100 \\
\hline \multicolumn{8}{|l|}{ Jumlah Serangan PJK } \\
\hline 1 kali & 8 & & 50,0 & 6 & 37,5 & 14 & 43,8 \\
\hline$>2$ kali & 8 & & 50,0 & 10 & 62,5 & 18 & 56,2 \\
\hline Total & 16 & & 100 & 16 & 100 & 32 & 100 \\
\hline
\end{tabular}

Hasil analisa lebih lanjut terhadap kesiapan pulang didapatkan bahwa ada perbedaan yang bermakna kesiapan pulang pasien PJK terdiri dari status personal, pengetahuan, kemampuan koping, dan dukungan $(\mathrm{p}=0,001 ; \alpha=0,05)$ yang dijelaskan dalam tabel 2 .

\section{Pembahasan}

Hasil penelitian menunjukkan bahwa terdapat pengaruh penerapan discharge planning terhadap kesiapan pulang pasien PJK di rumah sakit Kota Bukittinggi. Pasien PJK mengalami penurunan fungsi jantung akibat dari suplai dan kebutuhan oksigen yang tidak seimbang sehingga pasien mengalami ketidakmampuan memenuhi kebutuhan perawatan dirinya sendiri secara mandiri dalam semua aspek kebutuhan meliputi biopsikososial (Hasymi, 2009).

Dijelaskan oleh Orem (2001) dalam teori Self Care Defisit bahwa upaya keperawatan dalam memenuhi kebutuhan individu dengan cara mengenal dan memenuhi kebutuhannya yaitu melalui supporting educative nursing system. Sistem pendukung edukasi diberikan dalam bentuk arahan, yaitu untuk memenuhi kebutuhan diri dengan cara memberikan dorongan secara fisik dan psikologis pada pasien, 
serta mengajarkan pasien mengenai prosedur dan aspek-aspek tindakan agar pasien dapat melakukan perawatan diri sendiri secara mandiri setelah kembali ke rumah. Discharge planning merupakan salah satu upaya mempersiapkan atau memandirikan pasien agar mampu melakukan perawatan terhadap diri sendiri mencapai kesiapan fisik, psikis, dan sosial (Potter \& Perry, 2006).

Pasien pasca serangan jantung yang disiapkan kepulangannya dengan diberikan konseling dan pendidikan kesehatan serta berbagi pengalaman penyakit yang diatur dalam bentuk grup konseling saat awal di rumah sakit sampai pulang ternyata efektif meningkatkan kesiapan pulang pasien secara fisik, psikis, sosial, dan spiritual. Kesiapan tersebut secara langsung meningkatkan kualitas hidup pasien PJK karena pasien paska serangan jantung sering mengalami penurunan kualitas hidup dapat berdampak terhadap penurunan kesehatan jantung (Bagheri, Memarian, \& Alhani, 2007). Berdasar penelitian tersebut, discharge planning yang terprogram dan terstruktur sangat efektif digunakan untuk meningkatkan kesiapan pulang pasien dan kemandirian pasien dalam memenuhi kebutuhan perawatan diri sendiri setelah pasien sampai di rumah. Kesiapan pulang tersebut terdiri dari status personal, pengetahuan, kemampuan koping, dan dukungan.

\section{Status Personal}

Status personal yang dirasakan oleh pasien diukur meliputi keyakinan pasien untuk pulang, kesiapan fisik, nyeri, kekuatan, energi, kesiapan emosional, dan stres. Program discharge planning juga terdapat tentang rehabilitasi jantung fase satu yaitu adanya pemberian pendidikan kesehatan PJK termasuk konseling, pengaturan diet, modifikasi faktor resiko, dan manajemen stres ditambah dengan latihan fisik. Rehabilitasi jantung terutama latihan fisik pada pasien PJK akan membantu menurunkan kadar total kolesterol dan LDL kolesterol penyebab utama terjadinya PJK.

Penurunan kolesterol membantu untuk mengurangi penyumbatan arteri koroner, dimana penyumbatan yang berkurang tersebut dapat menyebabkan suplai oksigen menjadi adekuat. Kemudian, dilanjutkan dengan pengurangan kerusakan sel otot jantung yang mengakibatkan nyeri dada berkurang, suplai oksigen ke jaringan jadi adekuat juga. Kelelahan dan kelemahan yang terasa berubah jadi bertenaga dan lebih berenergi. Dengan demikian, rehabilitasi jantung fase satu diyakini dapat mengurangi nyeri, menjadi bertenaga dan benergi, dan mempengaruhi kesiapan fisik dan kesiapan pulang pasien (Yahya, 2010).

Pengaruh dari rehabilitasi jantung tidak hanya mengurangi gejala fisik melainkan mempengaruhi pengurangan gejala secara psikososial seperti cemas dan stres akibat dari serangan PJK. Latihan fisik dapat meningkatkan tonus otot, mengurangi ketegangan, meningkatkan relaksasi, mengurangi risiko penyakit kardiovaskuler, serta meningkatkan fungsi kardiovaskuler. Latihan fisik yang dilakukan secara efektif dapat meningkatkan pelepasan opioid endogen yang menciptakan perasaan sejahtera untuk mengurangi rasa cemas dan stres (Potter \& Perry, 2005).

\section{Pengetahuan}

Khan, et al. (2006) mengemukakan bahwa pasien yang mengalami serangan jantung sebagian besar kurang pengetahuan tentang gejala akan terjadinya serangan jantung, nyeri dada, palpitasi, diaforesis dengan angka statistik sebesar $63 \%$ dari 720 orang sehingga terlambat dibawa ke rumah sakit sampai menyebabkan kematian mendadak. Khan, et al. (2006) juga melakukan penelitian terjadinya PJK akibat ketidaktahuan pasien tentang faktor resiko penyebab terjadinya PJK didapatkan 68\% pasien memiliki pengetahuan yang rendah. Saran dari kedua hasil penelitian ini, Khan, et al. menyarankan bahwa agar pasien diberikan pengetahuan tentang PJK.

Discharge planning merupakan stimulus yang diberikan melalui media yang melibatkan indra penglihatan dan pendengaran setelah itu stimulus ditransfer kedalam otak untuk melakukan proses berfikir dan mempertimbangkan terhadap stimulus. 
Stimulus yang diterima kemudian dicoba untuk dilakukan sehingga timbul keyakinan terjadinya kemandirian dalam merawat diri dan kesiapan untuk mencegah terjadinya kekambuhan.

\section{Kemampuan Koping}

Kondisi psikologis pasien setelah mendapatkan serangan jantung atau menderita PJK sering mengalami kecemasan, khawatir, ketidakpastian dan ambigu, takut akan timbul serangan jantung lagi, dan kerusakan kesehatan, serta kebosanan. Kecemasan dan depresi mempengaruhi kualitas hidup, kepatuhan, dan prognosis pasien PJK.

Sebanyak 10,8\% pasien paska serangan jantung mengalami depresi namun gejalanya $40 \%$ sudah ada, seperti khawatir dan cemas. Strategi koping yang seharusnya digunakan pasien paska serangan jantung adalah konfrontasi, optimis, kemandirian. Akan tetapi, mekanisme koping yang paling sering dilakukan oleh kebanyakan pasien paska serangan jantung adalah koping yang diekspresikan dengan cemas dan depresi (Daly, et al., 2000).

Discharge planning merupakan strategi mekanisme koping dalam mempersiapkan pasien pulang ke rumah dari rumah sakit dengan keadaan yang tidak mengalami kecemasan dan depresi paska serangan PJK sehingga pasien memiliki kemampuan koping setelah sampai di rumah. Menurut Potter dan Perry (2005), pemberian pengajaran dan pembelajaran terkait masalah koping adalah cara perawatan di rumah, yakni seperti obat-obatan, diet, aktifitas, rehabilitasi lanjutan, dan pencegahan komplikasi.

\section{Dukungan}

Intervensi keperawatan terkait kegiatan discharge planning diberikan dengan tujuan untuk membantu mempersiapkan pasien dan keluarga merawat pasien serta pendukung yang lainnya hingga dapat menunjang perbaikan di rumah sampai pasien di rumah (Bullecheck, Butcher, \& Docterman, 2008).

Tabel 2. Perbedaan Kesiapan Pulang pada Pasien PJK antara Kelompok Kontrol dan Kelompok Intervensi

\begin{tabular}{|c|c|c|c|c|c|c|c|}
\hline Variabel & $\mathbf{N}$ & Mean & SD & $\mathbf{S E}$ & $\mathbf{t}$ & $\begin{array}{c}\text { Mean Diff } \\
95 \%\end{array}$ & $\mathbf{p}$ \\
\hline \multicolumn{8}{|l|}{ Kesiapan Pulang } \\
\hline Kontrol & 16 & 100,00 & 3,48 & 0,87 & 60,03 & 108,31 & $0,001 *$ \\
\hline Intervensi & 16 & 208,31 & 6,32 & 1,58 & & 104,$58 ; 112,04$ & \\
\hline \multicolumn{8}{|l|}{ Status Personal } \\
\hline Kontrol & 16 & 33,75 & 1,44 & 0,36 & 48,99 & 30,13 & $0,001 *$ \\
\hline Intervensi & 16 & 63,88 & 1,99 & 0,49 & & 28,$87 ; 31,39$ & \\
\hline \multicolumn{8}{|l|}{ Pengetahuan } \\
\hline Kontrol & 16 & 10,81 & 2,19 & 0,55 & 56,44 & 54,06 & $0,001 *$ \\
\hline Intervensi & 16 & 64,88 & 3,14 & 0,79 & & 52,$10 ; 56,03$ & \\
\hline \multicolumn{8}{|c|}{ Kemampuan Koping } \\
\hline Kontrol & 16 & 22,38 & 1,63 & 0,41 & 20,28 & 12,88 & $0,001 *$ \\
\hline Intervensi & 16 & 35,25 & 1,95 & 0,49 & & 11,$58 ; 14,17$ & \\
\hline \multicolumn{8}{|l|}{ Dukungan } \\
\hline Kontrol & 16 & 33,06 & 3,07 & 0,77 & 12,25 & 11,25 & $0,001 *$ \\
\hline Intervensi & 16 & 44,31 & 2,02 & 0,51 & & 9,$36 ; 13,14$ & \\
\hline
\end{tabular}

*Bermakna pada $\alpha=0,05$ 
Discharge planning yang diberikan dengan cara komprehensif dan ditambah dengan ada dukungan setelah pulang pada pasien jantung yang bermakna dapat mengurangi readmission dan meningkatkan kesehatan seperti kelangsungan hidup dan kualitas hidup (Phillips, et al., 2004).

Penyebab kematian pada paska serangan jantung tertinggi yaitu tingkat depresi dan kurang dukungan sosial. Dukungan sosial dipercaya dalam kesiapan pulang yaitu dukungan instrumental dan emosional (Bomar, 2004; Kaakinen, Duff, Coehlo, \& Hanson, 2010). Adanya dukungan sosial terutama keluarga terhadap anggota keluarganya yang menderita PJK sangatlah penting peranannya dalam proses penyembuhan. Dalam menjalankan peran keluarga maka keluarga harus memahami tentang cara merawat pasien PJK.

Ketidaktahuan pihak keluarga akan mempengaruhi perubahan sistem keluarga yang dapat menghambat proses penyembuhan dan kemungkinan berdampak negatif terhadap keutuhan rumah tangga (Moser \& Riegel, 2008). Dukungan sosial yang diberikan dengan cara sederhana dan mendasar yaitu melalui dukungan emosional dan intimasi. Dukungan yang diberi dalam bentuk dukungan emosional berupa penghargaan, instrumental, informasi, dan jaringan sosial serta dukungan kerabat atau teman. Sedang intimasi yang dimaksud merupakan intim secara emosional, sosial, seksual, intelektual, dan rekreasi (Hasymi, 2009).

Penelitian ini memiliki beberapa keterbatasan, terutama pada proses penelitian yaitu periode memberikan program discharge planning lebih singkat dari yang dianjurkan teori dimana untuk mendapat perubahan perilaku yang memerlukan waktu minimal 12 minggu. Disamping itu, selama proses penelitian, kehadiran anggota keluarga yang sering berganti-ganti diduga kurang memberi dukungan optimal pada pasien untuk melaksanakan program.

Implikasi hasil penelitian ini berdampak secara tidak langsung terhadap pemahaman perawat mengenai discharge planning, yang memberikan dampak terhadap pemahaman pada pasien sehingga pasien merasa nyaman, puas dan mempercepat hari rawat inap pasien di rumah sakit serta mencegah terjadi readmission. Implikasi tersebut membantu teraplikasinya peran perawat.

Implikasi lain adalah dengan menjadikan salah satu model atau asuhan keperawatan pelayanan keperawatan medikal bedah, sehingga perawat juga dituntut mempunyai kemampuan melakukan skoring tingkat kesiapan pulang pasien. Penerapan discharge planning memberikan inspirasi baru terhadap penelitian yang terkait dengan penerapan discharge planning melalui teknologi yang canggih dan media pembelajaran yang up to date.

\section{Kesimpulan}

Penelitian ini memberikan gambaran karakteristik pasien PJK yang dirawat di Kota Bukittinggi yaitu rerata berusia 53,50 tahun, jenis kelamin terbanyak adalah laki-laki dengan tingkat pendidikan SMU, status perkawinan yang paling terbanyak adalah berstatus kawin atau menikah, dan bila dilihat dari jumlah serangan PJK paling banyak pasien PJK sudah mengalami serangan $\geq 2$ kali serangan.

Rata-rata kesiapan pulang yang dirasakan pasien PJK yang terdiri dari status personal, pengetahuan, kemampuan koping, dan dukungan lebih tinggi pada kelompok intervensi dibandingkan dengan kelompok kontrol. Hasil penelitian menunjukkan bahwa terdapat perbedaan yang bermakna antara kesiapan pulang pasien PJK yang terdiri dari status personal, pengetahuan, kemampuan koping, dan dukungan antara kelompok kontrol dan kelompok intervensi.

Mengingat penting dan bermanfaatnya penerapan discharge planning sebagai upaya peningkatan kualitas asuhan keperawatan maka diharapkan para perawat mampu untuk mensosialisasikan dan melaksanakan discharge planning, membantu dan menyusun Standard Operational Procedure (SOP) mengenai discharge planning rumah sakit, 
membentuk tim discharge planner yaitu dengan memberdayakan perawat berpendidikan tinggi (Ners), menjadikan discharge planning sebagai intervensi keperawatan, serta membentuk klub jantung sehat dengan membentuk peer educative atau group counseling.

Untuk penelitian selanjutnya yang terkait dengan discharge planning, perlu dikembangkan dan ditingkatkan lebih lanjut. Bagi institusi pendidikan keperawatan diharapkan memperkenalkan dan menjadikan discharge planning sebagai acuan materi pokok di dalam kelas dan diharapkan dapat menerapkan di lahan praktek atau di rumah sakit saat melakukan praktek klinik (JH, ENR, TN).

\section{Referensi}

Bagheri, H., Memarian, R., \& Alhani, F. (2007). Evaluation of the effect of group counselling on post myocardial infarction patient: Determined by an anlysis of quality of life. Journal Of Clinical Nursing, 16 (2), 402-406. Doi: $10.1111 / \mathrm{j} .1365-2702.2005 .01498 . \mathrm{x}$

Bomar, P.J. (2004). Promoting health in families: Applying family research and theory to nursing practice. Philadelphia: WB. Saunders Company.

Bulecheck, G.M., Butcher, H.K., \& Dochterman, J.M. (2008). Nursing interventions classification (NIC) (5th Ed.). St. Louis, Missouri: Mosby, Inc.

Cawthorn, L. (2005). Discharge planning under the umbrella of advanced nursing practice case manager. Canada: Longwoods Publishing.

Daly, J., Elliot, D., Cameron-Traub, E., Salamonson, Y., Davidson, P., Jackson, D., et al. (2000). Health status, perceptions of coping, and social support immediately after discharge of survivors of acute myocardial infarction. American Journal Of Critical Care, 9 (1), 62-70.

Hasymi, Y. (2009). Pengaruh dukungan sosial keluarga dan intimasi terhadap persepsi tingkat nyeri pada pasien miokard infark di RSUD Dr. M. Yunus Bengkulu (Master tesis, tidak dipublikasikan). Program Pascasarjana Fakultas Ilmu Keperawatan Universitas Indonesia, Jakarta.
Kaakinen, J.R., Duff, V.G., Coehlo, D.P., \& Hanson, S.M.H. (2010). Family health care nursing: Theory, practice, \& research (4th Ed.). Philadephia: F.A Davis Company.

Khan, M.S., Jafary, F.H., Jafar, T.H., Faruqui, A.M., Rasool, S.I., Hatcher, J., \& Chaturvedi, N. (2006). Knowledge or modifiable risk factors of heart diseases among patients with acute myocardial infarction in Karachi, Pakistan: A cross sectional study. Researcher Article, BMC Cardiovascular Disorder, 6 (18). doi:10.1186/1471-2261-6-18.

Moser, D.K., \& Riegel, B. (2008). Cardiac nursing: A companion braunwald's heart disease. Philadelphia: Saunders Elsevier.

Orem, D.E. (2001). Nursing concepts of practice (6th Ed.). St. Louis, Missouri: Mosby.

Phillips, C.O., Wright, S.M., Kern, D.E., Singa, R.M., Shepperd S., \& Rubin, H.R. (2004). Comprehensive discharge planning with postdischarge support for cardiac patient. Journal American Medical Association, 291 (11), 1358-1367. Doi:10.1001/jama.291.11.1358.

Potter, P.A., \& Perry, A.G. (2005). Buku ajar fundamental keperawatan: Konsep, proses, dan praktik (Edisi 4, Vol. 1). (Yasmin, dkk., Alih Bahasa). Jakarta: Penerbit Buku Kedokteran EGC.

Potter, P.A., \& Perry, A.G. (2006). Buku ajar fundamental keperawatan: Konsep, proses, dan praktik (Edisi 4, Vol 2). (Yasmin, dkk., Alih Bahasa). Jakarta: Penerbit Buku Kedokteran EGC.

Weiss, M., \& Piacentine, L. (2006). Psychometric properties of the readiness for hospital discharge scale. Journal of Nursing Measurement, 13 (3), 163-180.

Yahya, A.F. (2010). Menaklukkan Pembunuh No.1: Mencegah dan mengatasi penyakit jantung koroner secara tepat dan cepat. Bandung: PT. Mizan Pustaka. 